book of advanced cardiac life support. Dallas: American Heart Association, 1981:VII-7.

7 St John Ambulance Association, British Red Cross Society. The first aid manual. London: Dorling Kindersley Ltd, 1982.

8 Kempf FC, Josephson ME. Cardiac arrest recorded on ambulatory electrocardiograms. Am $\mathcal{F}$ Cardiol 1984;53:1577-8

9 Campbell RWF, Murray A, Julian DG. Ventricular arrhythmias in first 12 hours of acute myocardial infarction. Natural history study. Br Heart $\mathcal{f} 1981 ; 46$ :

10 Adgey J. Pre-hospital coronary care with a mobile unit. In: Colling J, ed. Coronary care in the community. London: Croom Helm, 1977:120.
11 Sclarovsky S, Kracoff OH, Agmon J. Acceleration of ventricular tachycardia induced by a chest thump. Chest $1981 ; 80: 596-9$.

12 Chamberlain DA. Management of arrhythmias. In: Maseri A, Goodwin J, eds. Hammersmith cardiology workshop series. Vol 1. New York: Raven Press, 1984. 3 Graf WS, Etkins P. Ventricular tachycardia after synchronized direct-current

14 Desilva RA, Graboys TB, Podrid PJ, Lown B. Cardioversion and defibrillation. Am Heart f 1980;100:881-95.

(Accepted 2 fuly 1985)

\title{
Snoring as a risk factor for disease: an epidemiological survey
}

\author{
PETER G NORTON， EARL V DUNN
}

\begin{abstract}
In a study conducted in four family practice units in Toronto, Canada, 2001 subjects reported on snoring and medical conditions in members of their households. For spouses the prevalence of snoring increased with age up to the seventh decade, with a higher prevalence of nearly $85 \%$ in husbands. For 11 medical problems an association existed between snoring, its frequency, and the presence of the condition. This association continued when the data were corrected for sex, age, and marital state. For hypertension both men and women who snored between the fifth and 10th decades had a twofold increase over non-snorers. The prevalence of heart disease and other conditions, except for diabetes and asthma, also increased in snorers in this age group. When corrected for smoking and obesity the association between snoring, hypertension, and heart disease persisted.

These findings extend those of Lugaresi et al, and if they could be confirmed snoring as a risk factor for conditions other than sleep apnoea and sleep disorders might be considered. Methods of alleviating the acoustic annoyance of snoring may also provide direct medical benefits.
\end{abstract}

\section{Introduction}

Snoring is a common condition. In a study of nearly 6000 people living in San Marino Lugaresi et al stated that $40 \%$ of men and $28 \%$ of women snored, with increasing prevalence up to the seventh decade, when over $60 \%$ of men and $40 \%$ of women were found to be habitual snorers. ${ }^{12}$ In an earlier study we found that snoring occurred in over half of the adult population, with $86 \%$ of wives reporting their husbands as snorers and $57 \%$ of husbands reporting their wives as snorers. ${ }^{3}$ Associated with sleep apnoea and other sleep disorders snoring has been a topic of medical discussion for several years and has even been considered a risk factor for sudden death in infants. ${ }^{45}$

Reports have recently speculated that snoring may be a risk factor for other diseases, ${ }^{6-9}$ and so its physiology ${ }^{10}$ and possible concurrent conditions are to be considered. ${ }^{112}$ Lugaresi et al have shown that snoring is associated with hypertension. ${ }^{211}$ In a previous unpublished pilot study we too noted that there

\footnotetext{
Department of Family and Community Medicine, University of Toronto, Ontario

PETER G NORTON, PHD, MD, assistant professor

EARL V DUNN, MD, professor
}

Correspondence and requests for reprints to: Dr Peter Norton, Sunnybrook Medical Centre, 2075 Bayview Avenue, Toronto, Ontario M4N 3M5. seemed to be an association between snoring and several medical problems, most notably hypertension, but we have found no reports that have considered the risk of snoring alone, unassociated with sleep apnoea or other conditions. We made this survey to see if such associations could be elicited.

\section{Methods}

We used a questionnaire tested in the pilot study mentioned above. Over 2000 visitors to four different family practice units in Toronto responded to questions about snoring in their households. The units where the questionnaire was administered serve different populations including upper, middle, and lower socioeconomic classes and several ethnic groups. Thus we hoped to get a broad ethnic and economic range within the sample. In each setting a sequential sample was taken of those who volunteered to answer the questionnaire (over $85^{\circ}$ of those approached), and the most common reason for refusal was that they were too busy to complete the questionnaire. A research assistant was present to make sure the questionnaire was completed correctly and answer any questions the respondents might have.

The reporters recorded basic demographic data about themselves and then listed all members of their households, completing a section for each member that ascertained whether he or she snored, how often, and conditions that made the snoring worse. The definition of snoring was a general one of noise produced while sleeping, but it was left to the reporters to interpret this as they saw fit, thus the definition was based on the respondent. The reporter noted on a provided list whether the reportee suffered from any of 13 general medical problems such as heart disease, chest disease, and allergies. Thus the data were not self reported but observed by members of the household. Medical records were not reviewed.

The responses to the questionnaire were collated and analysed with a computer program developed by ourselves. Each response could be analysed in relation to both the reporter and the reportee. For the total sample the group who were reported to snore every night, those who were reported to snore nearly every night, and the group of occasional snorers and non-snorers were compared using the $\chi^{2}$ test for trend with weights of six, five, three, and one, respectively. ${ }^{13}$ Levels of significance of 0.001 are shown. Other data were analysed with the $\chi^{2}$ statistic comparing snorers with non-snorers. Levels of significance of 0.05 and 0.01 are given.

\section{Results}

Within the four units 2054 questionnaires were completed, with over 500 from each site. After incomplete or unusable questionnaires were eliminated (early in the study some respondents completed data only on snorers even though they were asked to complete the items for all members of the household) 2001 usable questionnaires remained, reporting on 2629 subjects.

The profile of the reporters was similar to the population of Toronto and included persons from all ages, ethnic backgrounds, and economic strata. The reporters included 691 men and 1304 women. In six cases the gender of the reporter was not recorded. Ages varied widely among 
the reporters with over 200 in each decade from the third to the eighth. Occupations also varied widely, with 512 persons reporting themselves as white collar workers, 432 retired, 234 blue collar workers, and 223 professionals. The ethnic origins of these groups varied, with 654 reporters listing themselves as Canadians, 621 Anglo Saxons, and 326 Europeans. Family income varied, the largest group (519) having a total family income of less than $\$ 10000$. Of the reporters, 646 lived alone and 692 lived with only one other person, and $760(38 \%)$ reporters recorded themselves as snorers and $1105(42 \%)$ of the members of their household as snorers.

The 2001 reporters provided data on 2629 subjects ( 1411 men, 1211 women, and seven with no recorded gender). Among this group 1105 people snored (42\%), 1379 did not, 133 people could not be classified by the reporter, and nine received no answers. The proportion of snorers varied according to the relationship to the reporter : $386(71 \%)$ husbands were reported and only $169(51 \%)$ wives. Among children $115(25 \%)$ sons snored and only $93\left(21^{\circ}\right)$ daughters. Of the other men in the house, $229\left(59^{\circ}\right.$ ) snored and only $143\left(35^{\circ}\right)$ other women. Table I shows the reported prevalence of snoring of spouses (probably

TABLE I-Snoring in husbands and wives by decades

\begin{tabular}{lrrrrrrr}
\hline Decade: & 3 & 4 & 5 & 6 & 7 & 8 & 9 \\
\hline Husbands $(\circ)$ & 60 & 65 & 71 & 83 & 84 & 77 & 60 \\
Wives $(\%)$ & 34 & 34 & 48 & 53 & 73 & 69 & 50
\end{tabular}

ported in Canada and the United States of America. ${ }^{14-16}$ For example, the reported prevalences of hypertension, diabetes, heart disease, obesity, and smoking all vary within a narrow range and our data were within the ranges for all these conditions. As a further check, a random sample of the population was derived from the directory of Toronto, and the questionnaire was sent to them. Although the prevalence of response for this sample was less than $20 \%$, the results were nearly identical with those of the analysed sample from the practice populations.

Snorers were more likely to have each of the 13 conditions than nonsnorers. For 11 of the 13 conditions the prevalence of problems in creased with the nightly amount of snoring, the exceptions being insomnia and asthma, and smoking and obesity occurred more often according to the amount of snoring .Table III shows the same medical conditions for those subjects who were aged over 40 (those more likely to have some illness), comparing snorers and non-snorers by sex. Again we found that for all conditions except diabetes and asthma and for both sexes snorers were reported to have more illnesses. In most cases the differences were fairly small and not significant. None the less, because these differences remained for most conditions and both sexes they were probably real. The most noticeable differences were for hypertension and heart disease. Table IV shows the differences between snorers and non-snorers for these two conditions for each decade from the fifth to the ninth. The differences were sustained with one exception: hypertension in women in their $70 \mathrm{~s}$. In all groups of snorers the proportion of husbands was higher, and they were more likely to be reported as snorers. When corrected for the proportion of husbands, however, the differences remained.

TABLE II-Medical problems and snoring. (Values are percentages)

\begin{tabular}{|c|c|c|c|c|c|}
\hline Condition & All & Non-snorers & $\begin{array}{l}\text { Occasional } \\
\text { snorers }\end{array}$ & $\begin{array}{l}\text { Those who snore } \\
\text { nearly every night }\end{array}$ & $\begin{array}{c}\text { Those who snore } \\
\text { every night }\end{array}$ \\
\hline $\begin{array}{l}\text { Overweight } \\
\text { Smoker* } \\
\text { Raised blood pressure* } \\
\text { Insomnia } \\
\text { Chest disease* } \\
\text { Heart disease* } \\
\text { Depression* } \\
\text { Alcoholism** } \\
\text { Diabetes* } \\
\text { Sleep during day* } \\
\text { Rheumatism* } \\
\text { Allergies** } \\
\text { Asthma } \\
\text { Other* }\end{array}$ & $\begin{array}{r}7 \cdot 2 \\
17 \cdot 9 \\
6 \cdot 2 \\
1 \cdot 3 \\
2 \cdot 2 \\
4 \cdot 2 \\
0 \cdot 8 \\
0.5 \\
1 \cdot 5 \\
1 \cdot 3 \\
4 \cdot 4 \\
11 \cdot 2 \\
2.9 \\
7 \cdot 3\end{array}$ & $\begin{array}{r}2.3 \\
10.3 \\
2.3 \\
0.6 \\
1.4 \\
1.7 \\
0.2\end{array}$ & $\begin{array}{r}8 \cdot 9 \\
24 \cdot 0 \\
8 \cdot 8 \\
1 \cdot 7 \\
2 \cdot 7 \\
5 \cdot 5 \\
1 \cdot 3 \\
0 \cdot 2 \\
2 \cdot 0 \\
2 \cdot 0 \\
7 \cdot 1 \\
13 \cdot 8 \\
5 \cdot 0 \\
8 \cdot 9\end{array}$ & $\begin{aligned} 16 \cdot 9 \\
32 \cdot 9 \\
12 \cdot 2 \\
5 \cdot 6 \\
4 \cdot 7 \\
9 \cdot 9 \\
2 \cdot 8 \\
2 \cdot 3 \\
2 \cdot 3 \\
4 \cdot 7 \\
8 \cdot 5 \\
14 \cdot 1 \\
3 \cdot 8 \\
11 \cdot 7\end{aligned}$ & $\begin{array}{r}22 \cdot 8 \\
33 \cdot 9 \\
18 \cdot 5 \\
1 \cdot 6 \\
5 \cdot 1 \\
11 \cdot 8 \\
2 \cdot 0 \\
2 \cdot 0 \\
3 \cdot 5 \\
3 \cdot 2 \\
9 \cdot 1 \\
14 \cdot 2 \\
2 \cdot 0 \\
15 \cdot 0\end{array}$ \\
\hline Total No in each group & 2629 & 1379 & 638 & 213 & 254 \\
\hline $\begin{array}{l}\text { Men }\left(0_{0}^{0}\right) \\
\text { Husbands }\left({ }_{0}^{\circ}\right)\end{array}$ & $\begin{array}{l}53 \cdot 7 \\
20 \cdot 9\end{array}$ & $\begin{array}{l}45 \cdot 4 \\
11 \cdot 7\end{array}$ & $\begin{array}{l}64 \cdot 2 \\
34 \cdot 9\end{array}$ & $\begin{array}{l}69 \cdot 0 \\
41 \cdot 8\end{array}$ & $\begin{array}{l}73 \cdot 2 \\
37 \cdot 8\end{array}$ \\
\hline
\end{tabular}

${ }^{*} \mathrm{p}<0.001, \chi^{2}$ test for trend; all tests for linearity NS.

TABLE III-Medical problems for fifth to 10th decades. (Values are percentages)

\begin{tabular}{|c|c|c|c|c|c|c|}
\hline \multirow[b]{2}{*}{ Condition } & \multicolumn{2}{|c|}{ All } & \multicolumn{2}{|c|}{ Men } & \multicolumn{2}{|c|}{ Women } \\
\hline & Snorers & Non-snorers & Snorers & Non-snorers & Snorers & Non-snorers \\
\hline $\begin{array}{l}\text { Overweight } \\
\text { Smoker } \\
\text { Raised blood pressure } \\
\text { Insomnia } \\
\text { Chest disease } \\
\text { Heart disease } \\
\text { Depression } \\
\text { Alcoholism } \\
\text { Diabetes } \\
\text { Sleep during day } \\
\text { Rheumatism } \\
\text { Allergies } \\
\text { Asthma } \\
\text { Other }\end{array}$ & $\begin{array}{r}20 \\
28 \\
20 \\
4 \\
5 \\
14 \\
2 \\
2 \\
4 \\
4 \\
15 \\
12 \\
3 \\
15\end{array}$ & $\begin{array}{l}6(0.001) \\
13(0.001) \\
10(0.001) \\
1(\mathrm{NS}) \\
3(\mathrm{NS}) \\
8(0.02) \\
0 \\
0 \\
4 \\
1(0.03) \\
9(0.03) \\
8(\mathrm{NS}) \\
2 \\
13\end{array}$ & $\begin{array}{r}21 \\
31 \\
20 \\
4 \\
6 \\
15 \\
1 \\
2 \\
5 \\
3 \\
9 \\
10 \\
2 \\
15\end{array}$ & $\begin{array}{r}10 \\
21 \\
9 \\
2 \\
5 \\
10 \\
0 \\
0 \\
6 \\
2 \\
7 \\
8 \\
3 \\
16\end{array}$ & $\begin{array}{r}18 \\
23 \\
21 \\
2 \\
5 \\
14 \\
3 \\
1 \\
3 \\
5 \\
24 \\
13 \\
4 \\
15\end{array}$ & $\begin{array}{r}5 \\
9 \\
10 \\
1 \\
2 \\
7 \\
0 \\
0 \\
3 \\
0 \\
10 \\
8 \\
2 \\
12\end{array}$ \\
\hline Total No in each group & 563 & 261 & 346 & 87 & 217 & 174 \\
\hline
\end{tabular}

those most reliably reported on). Both husbands and wives were reported to snore more often as their age increased up to the seventh decade. At all ages husbands were more likely to be reported as snorers. No differences existed between groups related to the reporter's occupation, ethnic background, or total family income. Those who reported themselves as snorers were more likely to report members of the family as snorers.

Table II shows the reported prevalence of several medical conditions. Although these data were not verified by chart audit, they were all within the fairly narrow ranges of community prevalences as re-
As both smoking and obesity are considered to be risk factors for hypertension and heart disease and showed the greatest differences between snorers and non-snorers the differences may be related to smoking and obesity and not to snoring. Table $\mathrm{V}$ shows the prevalence of hypertension and heart disease for both men and women and for the three factors smoking, overweight, and snoring with all combinations of these. Even when corrected for smoking and overweight for both sexes snorers were more likely to have heart disease or hypertension than non-snorers. Contrasted with non-snorers, men who snored and did not smoke and were not overweight had an increased prevalence 
of hypertension $(2 \cdot 2)$ and heart disease (1.2). If all three factors were present in the man the increased risks were $4 \cdot 2$ and $2 \cdot 0$. For women similar increases in prevalence of disease occurred with even higher risks.

\section{Discussion}

In this study we found that $42 \%$ of all people were reported to snore: over $70 \%$ of husbands and just over $50 \%$ of wives. The prevalence of snoring increased with age up to the seventh decade and then decreased slightly. These findings are similar to those of Lugaresi et al, ${ }^{1}$ but we found a higher prevalence of asleep ${ }^{4}$ could be the causative factors for the associations that we have shown.

Our findings reproduce and enlarge on those of Lugaresi et al and give strong evidence that snoring is associated with an increased risk for cardiovascular diseases, especially hypertension. We found that men who snored, smoked, and were obese had a risk of hypertension $4 \cdot 2$ times greater than non-snorers. Berry and Block have recently shown that positive pressure on the nasal airway reduces both the frequency of snoring and the desaturation of oxygen in heavy snorers. ${ }^{17}$ Case reports and personal experience of the authors indicate that to stop smoking or lose weight, or both, can reduce snoring considerably in some

TABLE IV-Hypertension and heart disease by decade and sex. (Values are percentages)

\begin{tabular}{|c|c|c|c|c|c|c|c|c|}
\hline \multirow[b]{3}{*}{ Decade } & \multicolumn{4}{|c|}{ Men } & \multicolumn{4}{|c|}{ Women } \\
\hline & \multicolumn{2}{|c|}{ Hypertension } & \multicolumn{2}{|c|}{ Heart disease } & \multicolumn{2}{|c|}{ Hypertension } & \multicolumn{2}{|c|}{ Heart disease } \\
\hline & Snorers & Non-snorers & Snorers & Non-snorers & Snorers & Non-snorers & Snorers & Non-snorers \\
\hline $\begin{array}{l}\text { Fifth } \\
\text { Sixth } \\
\text { Seventh } \\
\text { Eighth } \\
\text { Ninth }\end{array}$ & $\begin{array}{r}7 \\
22 \\
28 \\
27 \\
12\end{array}$ & $\begin{array}{l}13 \\
14 \\
13 \\
11\end{array}$ & $\begin{array}{r}5 \\
8 \\
17 \\
29 \\
43\end{array}$ & $\begin{array}{l}14 \\
20 \\
33\end{array}$ & $\begin{array}{l}12 \\
10 \\
15 \\
40 \\
40\end{array}$ & $\begin{array}{l}27 \\
25 \\
17\end{array}$ & $\begin{array}{r}12 \\
7 \\
29 \\
40\end{array}$ & $\begin{array}{r}2 \\
4 \\
4 \\
25 \\
25\end{array}$ \\
\hline
\end{tabular}

TABLE V-Prevalence of disease compared with smoking, obesity, and snoring. (Values are \% (numbers) of cases)

\begin{tabular}{|c|c|c|c|c|}
\hline & \multicolumn{2}{|c|}{ Men } & \multicolumn{2}{|c|}{ Women } \\
\hline & Hypertension & Heart disease & Hypertension & Heart disease \\
\hline $\begin{array}{l}\text { None } \\
\text { Smoking } \\
\text { Obesity } \\
\text { Smoking and obesity } \\
\text { Snoring } \\
\text { Snoring and smoking } \\
\text { Snoring and obesity } \\
\text { All }\end{array}$ & $\begin{array}{l}8(60) \\
11(17) \\
12(8) \\
0(2) \\
19(187) \\
15(85) \\
29(51) \\
35(23)\end{array}$ & $\begin{array}{r}13 \\
5 \\
0 \\
15 \\
9 \\
16 \\
26\end{array}$ & $\begin{aligned} 7(149) \\
37(16) \\
22(9) \\
0(0) \\
20(138) \\
10(39) \\
39(28) \\
33(12)\end{aligned}$ & $\begin{array}{r}8 \\
6 \\
0 \\
13 \\
13 \\
11 \\
25\end{array}$ \\
\hline
\end{tabular}

snoring in all categories. As reported by Lugaresi et al we found that snoring is associated with an increase in cardiovascular disease (especially hypertension) ${ }^{211}$ and most other common chronic medical conditions. Snoring is particularly associated with obesity and smoking, both of which have been implicated in the prevalence of cardiovascular and other medical problems. When we analysed our data those subjects who were not overweight and did not smoke but snored continued to have an increased prevalence of cardiovascular disease. Thus we concluded that an association exists between snoring and cardiovascular and other medical conditions.

Several authors have speculated on the reasons why snoring might be associated with increased risks of morbidity and mortality. ${ }^{5-8}$ It has been shown that some snorers have pulmonary hypertension during sleep ${ }^{10}$ and that some children who snore have clinical and electrocardiographical findings of pulmonary hypertension. ${ }^{12}$ This pulmonary hypertension and the excess desaturation of oxygen found in some snorers while they are people. Similarly, corrections of anatomical abnormalities have been reported to relieve some snorers. In the light of our findings investigation of the effects of these and other corrective measures for snoring with respect to people's health is warranted.

\section{References \\ 1 Lugaresi E, Coccagna G, Cirignotta F. Snoring and its clinical implications. In: Dement WC, eds. Sleep apnea syndromes. New York: A R Liss, $978: 13-21$ \\ 2 Lugaresi E, Cirignotta F, Coccagna G, Piana C. Some epidemiological data on (1980;3:221-4. \\ orton PG, Dunn EV, Haight JSJ. Snoring in adults: some epidemiologic aspects. \\ Can Med Assoc F 1983;128:674-5.
4 Block AJ, Boysen PG, Wynne JW, Hunt LA. Sleep apnea, hypopnea and oxygen desaturation in normal subjects: a strong male predominance. $N$ Engl $\mathcal{F}$ Med $1979 ; 300: 513-7$ \\ 5 Turino GM, Goldring RM. Sleeping and breathing. N Engl f Med 1978;299: 1009-11. \\ Zwillich C. The clinical significance of snoring. Arch Intern Med 1979;139:24. \\ ctbrook PR. The chronically snoring child: an acoustic annoyance or cause for concern? Mayo Clin Proc 1983,58:39g. \\ Tobin MJ, Cohn MA, Sackner MA. Breathing 1984;289:335-6. Intern Med 1983;143:1221-8. \\ 11 Mondini S, Zucconi M, Cirignotta F, et al. Snoring as a risk factor for cardiac and circulatory problems: an epidemiological study. In: Guillemault C, Lugaresi E, eds. Sleep wake disorders: natural history, epidemiology and long- term evolution. New York: Raven Press, 1983 . \\ 12 Wilkinson AR, McCormick MS, Freeland AP, Pickering D. Electrocardiographic signs of pulmonary hypertension in children who snore. Br Med $\mathcal{F} 1981 ; 282$ : \\ 13 Armitage $P$. Tests for linear trends in proportions and frequencies. Biometrics $1955 ; 11: 375-86$ \\ 4 Department of Health and Human Services. Health. Washington: Department of Health and Human Services, 1981. (DHHS No 82-1232.) \\ 15 Statistics Canada. Health of Canadians; a report of the Canada health survey. 16 Ontario Council of Health. Hypertension. Ontario: Ontario Council of Health, 1977 \\ 17 Berry RB, Block AJ. Positive nasal airway pressure eliminates snoring as well as obstructive sleep apnea. Chest $1981 ; 85: 15-20$. \\ (Accepted 4 fune 1985)}

\section{SHORT REPORTS}

\section{Carbamazepine induced systemic lupus erythematosus: case report}

Anticonvulsants (phenytoin and ethosuximide) have been implicated in drug induced systemic lupus erythematosus. ${ }^{1}$ Carbamazepine (Tegretol), however, which is widely used in the treatment of grand mal and complex partial seizures, has not been definitely incriminated in this disease. I report a case of systemic lupus erythematosus associated with carbamazepine which resolved rapidly on withdrawal of the drug.

\section{Case report}

The patient, a 30 year old housewife, initially presented with complex partial seizures. Investigation disclosed a space occupying lesion in the right temporal lobe and at operation a grade II astrocytoma was partially removed. Her seizure disorder persisted postoperatively and was treated with carbamazepine $1 \mathrm{~g}$ and phenobarbitone $120 \mathrm{mg}$ daily.

A year later she developed pain and stiffness of her joints, affecting hands, feet, wrists, elbows, knees, and hips. She noticed a blotchy rash on her hands and feet and her eyes became sore and itchy. During hospital admission she developed pleuritic chest pain. Examination findings were normal apart from a vasculitic rash on hands and feet. There was no joint swelling and results of an ophthalmological examination were normal. Investigations 